\title{
Frequently assessed and used prognostic factors for outcome after macular hole surgery: which is better?
}

\author{
M. Roth ${ }^{1 *}$, N. Schön ${ }^{2}$, L. Jürgens ${ }^{1}$, D. Engineer ${ }^{2}$, K. Kirchhoff $^{2}$, R. Guthoff ${ }^{1}$ and J. Schmidt ${ }^{2,3}$
}

\begin{abstract}
Background: The aim of this retrospective study was to evaluate commonly used clinical and OCT-morphological parameters, including perifoveal pseudocysts, as prognostic factors for postoperative outcome after macular hole surgery in a retinal referral clinic in North Rhine-Westphalia, Germany.

Methods and material: This was a retrospective analysis of all patients who underwent surgery because of idiopathic MH between 2011 and 2017 in Augenklinik Tausendfensterhaus, Duisburg, Germany. Statistical evaluation of clinical and OCT-based parameters, including the areas of intraretinal pseudocysts, was conducted. The main statistical outcomes were surgical success and visual acuity. Only parameters with a highly significant correlation to the outcome parameters (postoperative visual acuity (VA); surgical success) in univariate analysis were entered in linear and logistic regression analyses.
\end{abstract}

Results: A total of 189 eyes of 178 patients (71.4\% female; mean age $67.5 \pm 8.2$ a) who underwent surgery because of $\mathrm{MH}$ were included. The overall closure rate was $86.8 \%$. The mean best corrected VA increased from $0.7 \pm 0.3 \log \mathrm{MAR}$ before surgery to $0.5 \pm 0.3 \operatorname{logMAR}(p<0.0001)$. While several clinical and OCT-based parameters as well as calculated indices showed a significant correlation with the outcome measures, the regression analysis showed that the minimum linear diameter was the only parameter that both predicted surgical success $(p=0.015)$ and was correlated with postoperative VA $(p<0.001)$.

Conclusion: The minimum linear diameter serves as an easily assessed prognostic factor with the best predictive properties. This result is of great importance for clinical practice, as it simplifies the postsurgical prognosis.

Keywords: Macular hole, Prognostic parameters, Vitreoretinal surgery, Optical coherence tomography, Vitrectomy

\section{Introduction}

A full-thickness macular hole $(\mathrm{MH})$ causes a reduction in visual acuity, central visual field scotoma and possibly metamorphopsias. Spontaneous closure is rare (4 to $11.5 \%$ [1]); thus, MH usually needs to be treated surgically by pars plana vitrectomy with fluid-gas exchange

\footnotetext{
*Correspondence: mathiasroth@gmx.net

1 Department of Ophthalmology, Heinrich-Heine University Düsseldorf,

Universitätsaugenklinik Düsseldorf, Moorenstr. 5, 40225 Düsseldorf, Germany

Full list of author information is available at the end of the article
}

and epiretinal and internal limiting membrane peeling. In a recent database study by Steel et al. with more than 1200 included operations, the success rate (corresponding to anatomical closure of the $\mathrm{MH}$ ) of surgical therapy reached almost 96\% [2]. In addition to common clinical parameters (e.g., age, duration of symptoms and preoperative visual acuity (VA)), several parameters measured by optical coherence tomography (OCT), such as minimum linear diameter, basal diameter, $\mathrm{MH}$ height, and indices based on those OCT measurements (macular hole index (MHI), diameter hole index (DHI) and tractional hole index (THI)), have been proposed as possible prognostic 
factors for surgical outcome and postoperative visual acuity [2-8] Additionally, the quantification of perifoveal pseudocysts might serve as a prognostic factor, but the relevant literature regarding this parameter is very limited thus far $[9,10]$. Opinions on which of those parameters might be the best prognostic factor are controversial. Thus, the aim of this retrospective study was to evaluate these commonly used clinical and OCT-morphological parameters as well as perifoveal pseudocysts as prognostic factors for postoperative outcome (anatomical closure of $\mathrm{MH}$, postoperative VA) in a relatively large cohort of patients with $\mathrm{MH}$ treated by surgeons in a busy retinal referral clinic in North Rhine-Westphalia, Germany.

\section{Methods and material}

Before initiation of this retrospective study, approval was obtained from the North Rhine Medical Association (Ärztekammer Nordrhein). The study adhered to the tenets of the Helsinki Declaration. In the inhouse registries of the eye clinic, all patients who had been treated because of MH from the 1st of January 2011 to the 31st of December 2017 were identified.

\section{Inclusion/exclusion criteria}

Only patients with an idiopathic full thickness macular hole regardless of axial length were included. Patients with lamellar macular holes were excluded. Furthermore, posttraumatic macular holes and patients with any other retinal disorder (e.g., AMD or diabetic retinopathy) or with previous retinal surgeries (e.g., after retinal detachment) or intravitreal injections were excluded.

\section{Parameters}

The following data were collected in the clinical records: age at surgery, sex, and duration from onset of symptoms until surgery. Best corrected visual acuity (VA) was assessed with standard optotypes at a $5 \mathrm{~m}$ distance before surgery and at a follow-up examination scheduled for 6 weeks after surgery. Axial length was measured with an IOL Master (Zeiss, Oberkochen, Germany). In the MH central cross-sectional image, taken with optic coherence tomography (OCT; Spectralis-OCT, Heidelberg Engineering, Germany) before surgery, the minimum linear diameter $(M L D)$, the base diameter $(B D)$ and the height $(H)$ were measured, and the macular hole index (MHI: max. Height/max. diameter), diameter hole index (DHI: min. Diameter/max. diameter) and tractional hole index (THI: max. Height/min. diameter) were calculated as previously described [6, 9, 11-14] (Fig. 1 A). For the minimum linear diameter (MLD), the minimum distance between the inner edges of the MH was measured parallel to the retinal pigment epithelium (RPE). The base diameter (BD) was defined as the diameter at the level of the RPE. The height $(\mathrm{H})$ was measured as the distance from the RPE to the innermost aspect of the MH. In a few cases of atypical MH, e.g., with a distinctly curved or skewed RPE, we plotted an approximated tangent line at the RPE and measured the diameters parallel to this line. In the fundus control image of the OCT image, the $\mathrm{MH}$ area (Ar) was manually marked and calculated in $\mathrm{mm}^{2}$ (Fig. 1B). The areas of the intraretinal pseudocysts (Cy) were measured in three cross-sectional OCT images (I: central to $\mathrm{MH}$, II and III superior and inferior tangential to $\mathrm{MH}$ ). The area was manually marked as a region of interest (ROI) in ImageJ (V. 1.52a; National Institutes of Health; Bethesda, Md., USA) and calculated as the sum of all ROIs per patient in pixels. Subfoveal fluid was excluded (Fig. 1C). Furthermore, all OCT images were examined for the presence of epiretinal membrane and vitreomacular traction.

Surgeries were performed by three surgeons with a comparable, very high level of experience. The surgical procedure was almost identical among the three surgeons (total pars plana vitrectomy, membrane peeling after application of indocyanine green (ICG) dye, postvitrectomy gas exchange with perfluoroethane gas) except for minor differences, e.g., only two surgeons regularly stained the vitreous with triamcinolone for better visualization. If indicated, phacoemulsification with intraocular lens implantation was performed before pars plana vitrectomy. After surgery, face-down positioning was recommended for 10 to 14 days as much as possible.

\section{Statistical evaluation}

Statistical analysis was performed using Prism 9.0.0 (GraphPad, La Jolla, California, USA). The normality of the distribution of the data was analyzed with the Shapiro-Wilk test. Data are presented descriptively with the median and interquartile range (presented as the median (25th percentile; 75 th percentile)). The visual acuity before treatment and at follow-up were compared with the nonparametric Wilcoxon matched pairs signed-rank test. For group comparisons, the Mann-Whitney U test was performed. Fisher's exact test, the chi-squared test and Spearman's $\mathrm{R}$ were used to investigate correlations. $P$ values $\leq 0.05$ were considered statistically significant. Linear and logistic regression analyses were performed on parameters that correlated highly significantly (min. $p \leq 0.01$ ) with postoperative VA, and that were highly significantly (min. $\mathrm{p} \leq 0.01$ ) different between the $M H$ closed and $M H$ persisting groups. In the regression models, the macular hole indices were omitted due to multicollinearity/redundancy of the data. In the linear regression analysis of the influence on the postoperative VA, only patients with a closed $\mathrm{MH}$ were included so that only parameters that had a direct influence on visual prognosis and not on 

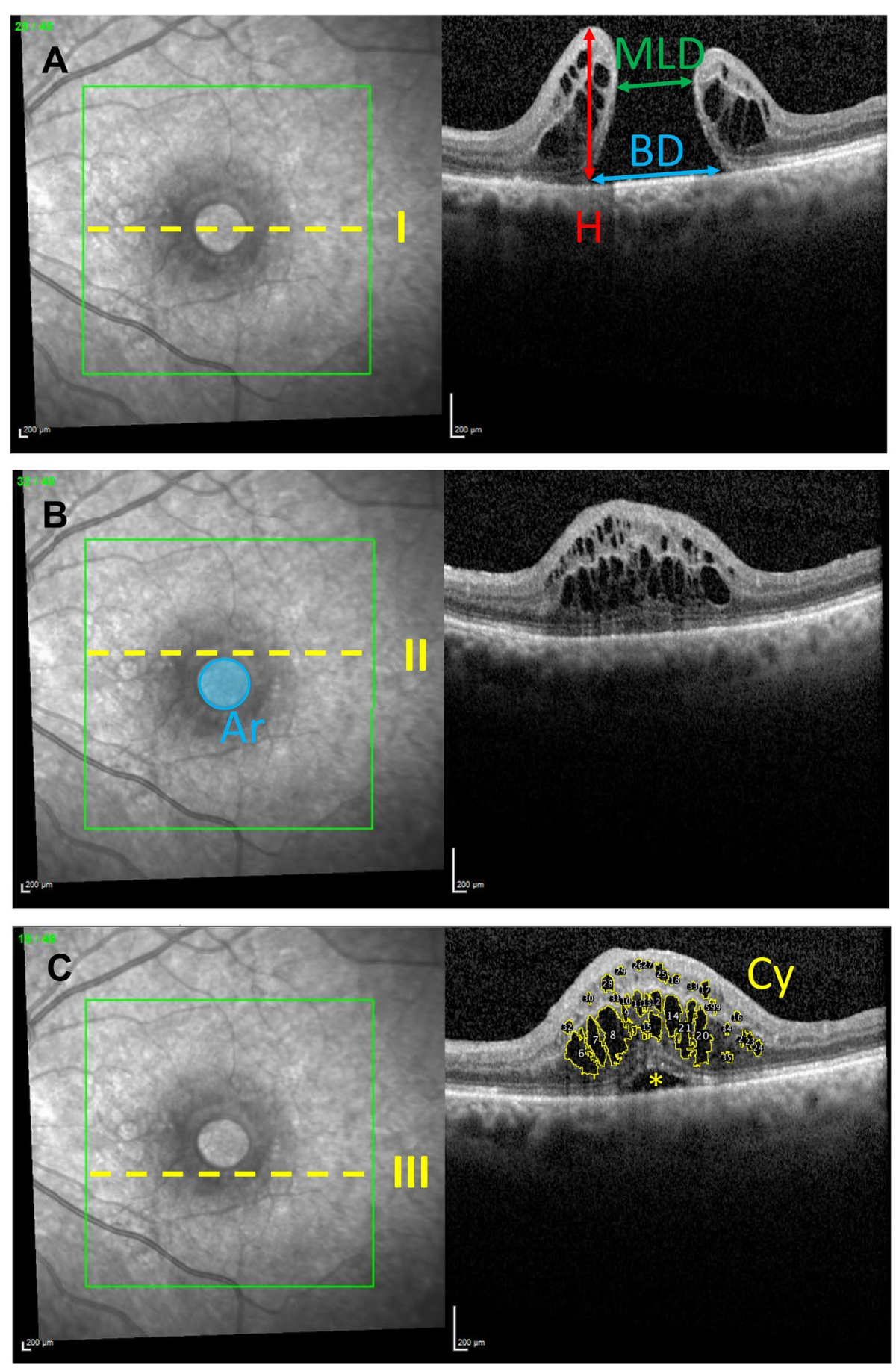

Fig. 1 Schematic presentation of the presurgical OCT-based measurements. A In the MH central cross-sectional image, the minimum linear diameter (MLD; green arrow), base diameter (BD; blue arrow) and height ( $\mathrm{H}$; red arrow) were measured. $\mathbf{B} \mathrm{In}$ the fundus control image of the OCT image, the $\mathrm{MH}$ area (Ar; blue area) was manually marked and calculated in $\mathrm{mm}^{2}$. C The areas of the intraretinal pseudocysts (Cy, yellow areas) were measured in three cross-sectional OCT images (I, II and II). Subfoveal fluid (yellow asterisk) was excluded from the calculation of the area (C). The yellow broken lines represent the location of the scans (I: central through $\mathrm{MH}, \mathrm{II}$ and III superior and inferior tangential to $\mathrm{MH}$, respectively) 


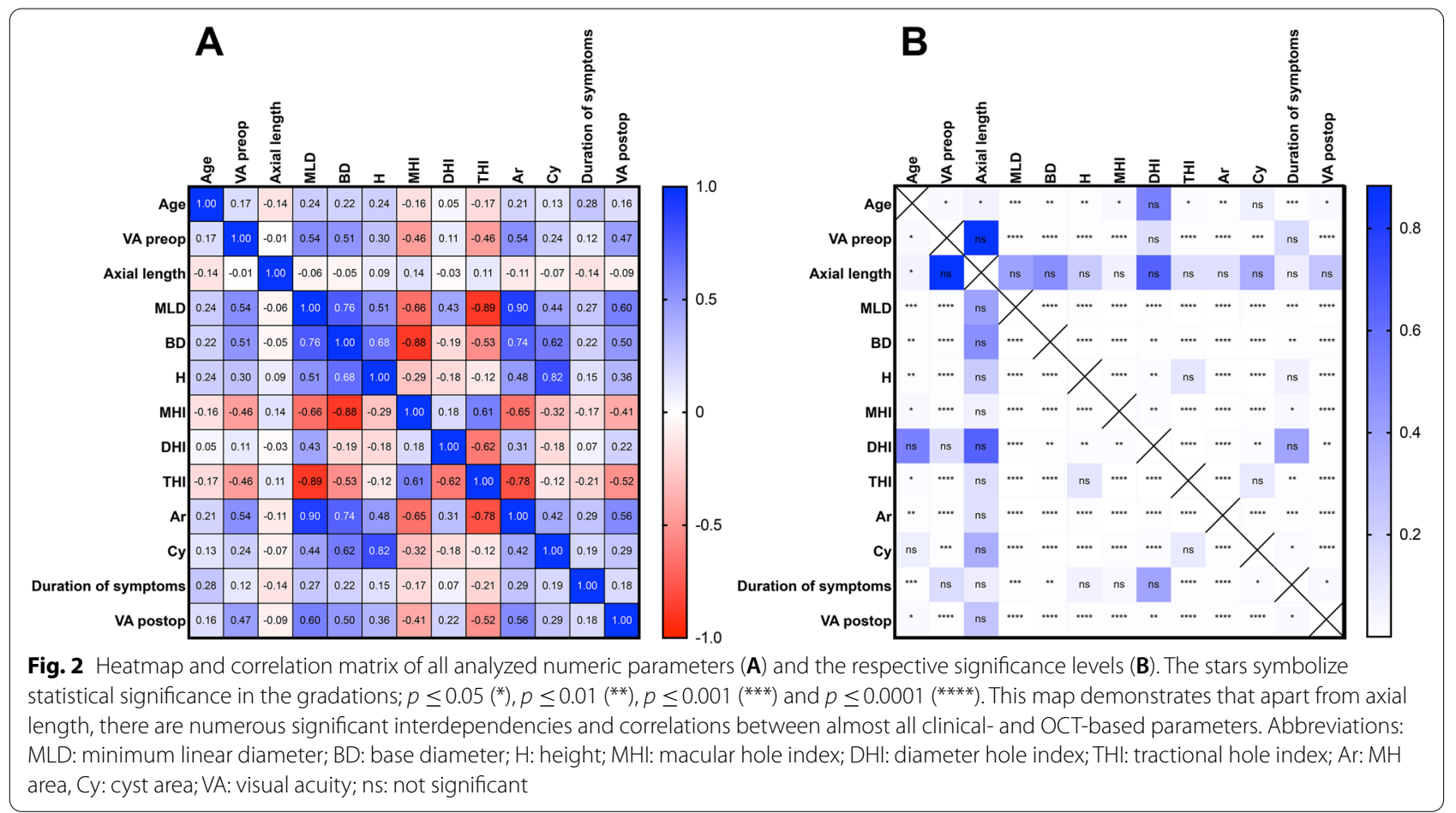

surgical failure with a subsequently significantly worse VA were evaluated.

\section{Results}

A total of 189 eyes of 178 patients (71.4\% female; mean age $67.5 \pm 8.2 \mathrm{y}$ ) who underwent surgery because of $\mathrm{MH}$ were included in the analysis. The female patients were on average younger (female: $66.6 \pm 8.0$ vs. male: $69.8 \pm 8.2 ; p=0.014)$. There were no sex-dependent differences in the other preoperative parameters or the closure rate. As the standard follow-up examination was scheduled for 6 weeks after surgery, the median follow-up time was $6(6 ; 6)$ weeks, with few deviations, ranging from 4 to 10 weeks. The overall closure rate was $86.8 \%(n=164)$. The mean best corrected visual acuity (VA) was $0.7 \pm 0.3 \operatorname{logMAR}$ before surgery, which significantly increased to $0.5 \pm 0.3 \operatorname{logMAR}$ postoperatively $(p<0.0001)$. Younger age showed a significant but weak correlation with better pre- and postoperative VA (age vs. VA preop: $p=0.0256 ; r=0.1668$; age vs. VA postop: $p=0.0256 ; r=0.1628$; see Fig. 2). While initially there was no difference in VA between males and females, postoperative VA was marginally worse in females (final VA female: $0.5(0.3 ; 0.8)$ vs. final VA male: $0.4(0.275 ; 0.6)$; $p=0.044)$. Each of the three surgeons treated approximately one-third of the cases (surgeons A 38\%, B 33\% and C 28\%). There was no difference in initial and final VA or in surgical success between the three surgeons. The use of triamcinolone and the lens status did not influence the closure rate or outcome of visual acuity.

When comparing patients with a closed $\mathrm{MH}(\mathrm{MH}$ closed group) to those with a persisting $\mathrm{MH}$ (MH persisting group) after surgery, there was no difference in sex distribution (Table 1). However, with respect to age, the two groups differed significantly. Patients with $\mathrm{MH}$ closure were on average 67 ((62; 72), range 49-91) years old, while those with a postoperative persisting macular hole were on average $70((63 ; 79) \mathrm{min} .43$ max. 88$)$ years old ( $p=0.033)$. Additionally, in the $M H$ closed group, the preoperative VA was significantly better than that in the $M H$ persisting group ( $M H$ closed: $0.7(0.5 ; 1,0)$ min. 0,1, max. 1,5 vs. $M H$ persisting: $1.0(0.8 ; 1.0)$ min. 0.4 , max. $1.5 ; p=0.0002)$. Naturally, the postoperative VA differed significantly between the $M H$ closed $(0.4(0.3 ; 0.6)$ min. 0 , max. 1,4) and $M H$ persisting $(0.9(0.8 ; 1.1)$ min. 0.5 , max. $1.9)$ groups $(p<0.0001)$. The difference in the duration of symptoms between the $\mathrm{MH}$ closed and $\mathrm{MH}$ persisting groups can be interpreted as a trend (MH closed: 42 (21; 120) days; min. 1 day, max. 720 days vs. MH persisting 105 (21; 270) days; min. 14 days, max. 720 days; $p=0.097$ ). The comparison of the morphologic parameters revealed differences between the groups for the minimum linear diameter (MLD) (MH closed: $281.5(198 ; 371) \mu \mathrm{m}$ vs. $M H$ persisting: $559(444 ; 633) \mu \mathrm{m} ; p<0.0001)$, the base diameter (BD) (MH closed: $752(522 ; 958) \mu \mathrm{m}$ vs. $M H$ persisting: $1.219(1028 ; 1668) \mu \mathrm{m} ; p<0.0001)$ and the maximal 
Table 1 Overview of the evaluated parameters

\begin{tabular}{|c|c|c|c|c|c|c|c|}
\hline & \multicolumn{2}{|l|}{ Overall } & \multicolumn{2}{|l|}{ Macular holes closed } & \multicolumn{2}{|l|}{ Macular holes open } & \multirow[b]{2}{*}{$\mathbf{p}$} \\
\hline & & $\mathbf{n}$ & & $\mathbf{n}$ & & $\mathrm{n}$ & \\
\hline & - & 189 & $86.7 \%$ & 164 & $13.2 \%$ & 25 & - \\
\hline Age (years) & $\begin{array}{l}67(63 ; 72) \\
\min .43, \max .91\end{array}$ & - & $\begin{array}{l}67(62 ; 72) \\
\min .49, \max .91\end{array}$ & - & $\begin{array}{l}70(63 ; 79) \\
\min .43, \max .88\end{array}$ & - & $0.033^{\#}$ \\
\hline Female & $71.4 \%$ & 135 & $70.7 \%$ & 116 & $76.0 \%$ & 19 & $0.812^{\S}$ \\
\hline Axial length (mm) & $\begin{array}{l}23.23(22.52 ; 23.64) \\
\min .23 .44, \max . \\
31.71)\end{array}$ & - & $\begin{array}{l}23.44(22.95 ; 24.37) \\
\min .20 .97, \max . \\
31.71)\end{array}$ & - & $\begin{array}{l}23.23(22.52 ; 23.64) \\
\min .20 .9, \max . \\
28.12)\end{array}$ & - & $0.061^{\#}$ \\
\hline Pseudophakia & $27.5 \%$ & 52 & $25.6 \%$ & 42 & $40.0 \%$ & 10 & $0.153^{\S}$ \\
\hline $\begin{array}{l}\text { Duration of symp- } \\
\text { toms (days) }\end{array}$ & $\begin{array}{l}49(21 ; 150) \\
\text { min. } 1, \max .720\end{array}$ & - & $\begin{array}{l}42(21 ; 120) \\
\min .1, \max .720\end{array}$ & - & $\begin{array}{l}105(21 ; 270) \\
\min .14, \max .720\end{array}$ & - & $0.097^{\#}$ \\
\hline VA preop (logMAR) & $\begin{array}{l}0.7(0.5 ; 1.0) \\
\min .0 .1, \max .1 .5\end{array}$ & - & $\begin{array}{l}0.7(0.5 ; 1.0) \\
\min .0 .1, \max .1 .5\end{array}$ & - & $\begin{array}{l}1.0(0.8 ; 1.0) \\
\min .0 .4, \max .1 .5\end{array}$ & - & $0.0002^{\#}$ \\
\hline $\operatorname{MLD}(\mu \mathrm{m})$ & $\begin{array}{l}299(209 ; 414.5) \\
\text { min. 19, max. } 1.067\end{array}$ & - & $\begin{array}{l}281.5(198 ; 371) \\
\min .19, \max .914\end{array}$ & - & $\begin{array}{l}559(444 ; 633) \\
\min .342, \max .1 .067\end{array}$ & - & $<0.0001^{\#}$ \\
\hline $\mathrm{BD}(\mu \mathrm{m})$ & $\begin{array}{l}793(537.5 ; 1046) \\
\text { min. } 163, \max .2147\end{array}$ & - & $\begin{array}{l}752(522 ; 958) \\
\text { min. } 163, \text { max. } 1674\end{array}$ & - & $\begin{array}{l}1219(1028 ; 1668) \\
\min .622, \max .2 .147\end{array}$ & - & $<0.0001^{\#}$ \\
\hline $\mathrm{H}(\mu \mathrm{m})$ & $\begin{array}{l}432(374 ; 492) \\
\text { min. } 203, \text { max. } 819\end{array}$ & - & $\begin{array}{l}422.5(365 ; 477) \\
\text { min. } 203, \max .819\end{array}$ & - & $\begin{array}{l}506(462 ; 594) \\
\text { min. 336, max. } 763\end{array}$ & - & $<0.0001^{\#}$ \\
\hline MHI & $\begin{array}{l}0.56(0.44 ; 0.75) \\
\min .0 .24, \max .1 .72\end{array}$ & - & $\begin{array}{l}0.61(0.48 ; 0.76) \\
\min .0 .24, \max .1 .72\end{array}$ & - & $\begin{array}{l}0.39(0.35 ; 0.49) \\
\min .0 .25, \text { max. } 0.67\end{array}$ & - & $<0.0001^{\#}$ \\
\hline DHI & $\begin{array}{l}0.41(0.31 ; 0.50) \\
\text { min. } 0.03, \text { max. } 0.92\end{array}$ & - & $\begin{array}{l}0.39(0.30 ; 0.50) \\
\text { min. } 0.03, \max .0 .92\end{array}$ & - & $\begin{array}{l}0.43(0.37 ; 0.55) \\
\text { min. } 0.21, \text { max. } 0.72\end{array}$ & - & $0.185^{\#}$ \\
\hline THI & $\begin{array}{l}1.43(1.10 ; 1.97) \\
\text { min. } 0.47, \text { max. } 19.27\end{array}$ & - & $\begin{array}{l}1.55(1.20 ; 2.05) \\
\min .0 .47, \max . \\
19.27\end{array}$ & - & $\begin{array}{l}0.90(0.74 ; 1.17) \\
\min .0 .58, \text { max. } 1.65\end{array}$ & - & $<0.0001^{\#}$ \\
\hline $\operatorname{Ar}(\mathrm{mm} 2)$ & $\begin{array}{l}0.09(0.06 ; 0.18) \\
\text { min. } 0.01 \text {, max. } 1.26\end{array}$ & - & $\begin{array}{l}0.08(0.05 ; 0.15) \\
\text { min. } 0.01, \max .1 .26\end{array}$ & - & $\begin{array}{l}0.27(0.19 ; 0.36) \\
\text { min. } 0.09, \text { max. } 0.96\end{array}$ & - & $<0.0001^{\#}$ \\
\hline Cy (pixels) & $\begin{array}{l}6897(2977 ; 10,643) \\
\min .0, \max .31,383\end{array}$ & - & $\begin{array}{l}6122.5(2667 ; \\
10,228) \\
\text { min. 0, max. 25,375 }\end{array}$ & - & $\begin{array}{l}10,851(8057 ; \\
19,008) \\
\text { min. 3388, max. } \\
31,383\end{array}$ & - & $<0.0001^{\#}$ \\
\hline $\begin{array}{l}\text { Vitreomacular } \\
\text { traction }\end{array}$ & $24.8 \%$ & 47 & $27.4 \%$ & 45 & $8.0 \%$ & 2 & $0.036^{\S}$ \\
\hline $\begin{array}{l}\text { Epiretinal mem- } \\
\text { brane }\end{array}$ & $24.8 \%$ & 47 & $23.9 \%$ & 39 & $32.0 \%$ & 8 & $0.315^{\S}$ \\
\hline Surgeon $A / B / C$ & $\begin{array}{l}\text { A: } 28.0 \% / B: 38.6 \% / C: \\
33.3 \%\end{array}$ & A: 53/B: 73/C:63 & $83.0 \% / 84.9 \% / 92.1 \%$ & A: 44/B: 62/C: 58 & $\begin{array}{l}\text { A: 17\%/B: 15.1\%/C: } \\
7.9 \%\end{array}$ & A: 9/B: 11/C: 5 & $0.301^{\$}$ \\
\hline Triamcinolon use & $64.00 \%$ & 121 & $87.6 \%$ & 106 & $12.4 \%$ & 15 & $0.66^{\S}$ \\
\hline $\begin{array}{l}\text { VA postop (log- } \\
\text { MAR) }\end{array}$ & $\begin{array}{l}0.4(0.3 ; 0.7) \\
\text { min. } 0, \max .1 .9\end{array}$ & - & $\begin{array}{l}0.4(0.3 ; 0.6) \\
\text { min. } 0, \max .1 .4\end{array}$ & - & $\begin{array}{l}0.9(0.8 ; 1.1) \\
\min .0 .5, \max .1 .9\end{array}$ & - & $<0.0001^{\#}$ \\
\hline
\end{tabular}

Overview of the evaluated parameters in the total cohort as well as a comparison between the parameters in the $\mathrm{MH}$ closed vs. MH persisting groups. All data except percentages are presented as the median with IQR (median (Q1; Q3)) and range (min., max.). Statistical tests applied: ${ }^{\#}$ Mann-Whitney U test; ${ }^{\$}$ Chi-square test; ${ }^{\S}$ Fisher's exact test; Abbreviations: $M L D$ minimum linear diameter, $B D$ base diameter, $H$ max. Height, $T H I$ tractional hole index, $M H I$ macular hole index, $D H I$ diameter hole index; $A r$ area of $\mathrm{MH}, \mathrm{Cy}$ areas of pseudocysts, $V A$ visual acuity; ns: not significant

height $(\mathrm{H})(M H$ closed: $422.5(365 ; 477)$ vs. $M H$ persisting: 506 (462; 594); $p<0.0001)$. Fifty-three MHs (28,0\%) had an MLD of $400 \mu \mathrm{m}$ or greater (22/53 open), and 30 MHs $(15,8 \%)$ had an MLD of $500 \mu \mathrm{m}$ or greater $(16 / 30$ open). Of the indices based on these measurements, only MHI and THI differed between the two groups (MHI: MH closed: 0.61 (0.48; 0.76) vs. $M H$ persisting: 0.39 (0.35; 0.49); $p$ <0.0001); THI: $M H$ closed: 1.55 (1.20; 2.05) vs.
MH persisting: 0.90 (0.74; 1.17); $p<0.0001)$, while DHI did not. Additionally, the area of the $\mathrm{MH}(\mathrm{Ar})$ and of the intraretinal pseudocysts $(\mathrm{Cy})$ were larger in $\mathrm{MH}$ persisting (Ar: $M H$ closed: $0.08(0.05 ; 0.15) \mathrm{mm}^{2}$ vs. $M H$ persisting: 0.27 (0.19; 0.36) $\mathrm{mm}^{2} ; p<0.0001 ; \mathrm{Cy}: M H$ closed: $6.122 .5(2.667 ; 10.228)$ pixel vs. $M H$ persisting: 10.851 (8.057; 19.008) pixel; $p<0.0001)$. Vitreomacular traction (VMT) was significantly more frequent in $\mathrm{MH}$ closed 
Table 2 Multiple logistic regression analysis of factors predicting surgical success ( $\mathrm{MH}$ closed)

\begin{tabular}{lllll}
\hline Parameter & Coefficient & $\mathbf{9 5 \%} \mathbf{C l}$ & $\mathbf{p}$ & Sign. level \\
\hline MLD & 0.006 & 0.001678 to 0.01249 & 0.015 & $*$ \\
BD & 0.002 & $-4.239 \mathrm{e}-005$ to 0.005160 & $0.068 \mathrm{~ns}$ \\
$\mathbf{H}$ & 0.001 & -0.007413 to 0.008960 & $0.735 \mathrm{~ns}$ \\
$\mathrm{Ar}$ & -0.569 & -8.378 to 3.570 & $0.835 \mathrm{~ns}$ \\
Cy & $<0.001$ & $-6.339 \mathrm{e}-005$ to & $0.407 \mathrm{~ns}$ \\
VA preop & -0.231 & -2.465 to 2.030 & $0.839 \mathrm{~ns}$ \\
\hline
\end{tabular}

In multiple logistic regression analysis, only parameters with highly significant differences ( $\min . \mathrm{p} \leq 0.01$ ) between the $\mathrm{MH}$ closed and $\mathrm{MH}$ persisting groups were included, and macular hole indices were omitted due to multicollinearity/ redundancy of the data. The aperture diameter was the strongest predictive factor for surgical success. Abbreviations: $C l$ confidence interval, $M L D$ minimum linear diameter, $B D$ base diameter, $H$ max. Height, $A r$ area of $\mathrm{MH}, C y$ area of pseudocysts, VA visual acuity; ns: not significant; * $p \leq 0.05$
( $M H$ closed: $27.8 \%,(n=45$ of 164 closed MHs) vs. $M H$ persisting: $8 \%$ ( $n=8$ of 25 persisting MHs); $p=0.036$ ). The median axial length was $23.39(22.87 ; 24.19) \mathrm{mm}$. There was no difference in the presence of the epiretinal membrane or axial length between the two groups. Multiple logistic regression analysis showed that the minimum linear diameter was the strongest predictive factor for surgical success (Table 2). Additionally, receiver operating characteristic (ROC) curve analysis showed the highest area under the curve value for the minimum linear diameter (Fig. 3 and Table 3).

Analogous to the surgical outcome, the morphologic parameters also had an influence on postoperative VA. Thus, a lower minimum linear and base diameter, a lower maximal height, a lower $\mathrm{MH}$ area, and lower areas of pseudocysts was correlated with a higher postoperative VA (Fig. 2). Among the indices, a lower MHI and THI

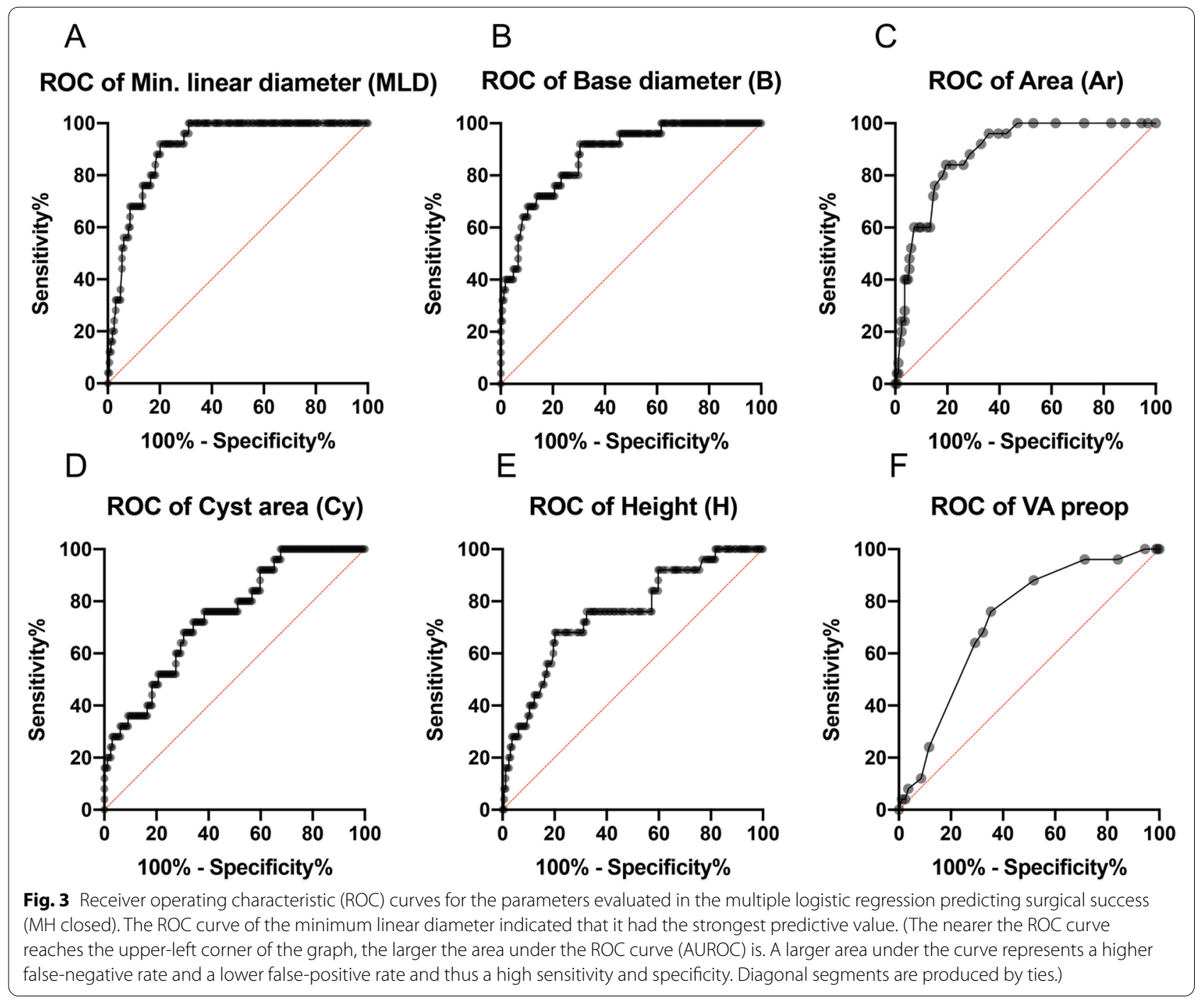


Table 3 ROC curve data and cutoff value

\begin{tabular}{llllllrr}
\hline Parameter & AUROC & 95\% Cl & Cutoff value & $\begin{array}{l}\text { Youden's } \\
\text { index (J) }\end{array}$ & Sensitivity (\%) & Specifity (\%) & p \\
\hline MLD & 0.9078 & 0.8624 to 0.9532 & $>392.5$ & 0.72 & 92 & 79.9 & $<0.0001$ \\
BD & 0.8757 & 0.8078 to 0.9437 & $>861.5$ & 0.61 & 92 & 69.5 & $<0.0001$ \\
H & 0.7548 & 0.6506 to 0.8589 & $>484.5$ & 0.48 & 68 & 84.9 & $<0.5$ \\
Ar & 0.8863 & 0.8308 to 0.9419 & $>0.1650$ & 0.64 & 100 & 32.3 & $<0.0001$ \\
Cy & 0.7427 & 0.6458 to 0.8396 & $>3337$ & 0.32 & 76 & 64.6 & 0.0001 \\
VA preop & 0.7256 & 0.6324 to 0.8188 & $>0.7500$ & 0.40 & 0003 \\
\hline
\end{tabular}

Table 3 shows the area under the curve (AUROC) and confidence interval (CI) of the receiver operating characteristic (ROC) curves (see Fig. 3 ) for the prognostic parameters analyzed in the regression models. The cutoff value was derived according to the maximum value of Youden's index (J). Sensitivity and specificity show the highest possible values at the cutoff value. Abbreviations: $\mathrm{Cl}$ confidence interval, $M L D$ minimum linear diameter, $B D$ base diameter; $H$ max. Height, $A r$ area of $M H, C y$ area of pseudocysts, $V A$ visual acuity

was correlated with a higher VA, while DHI inversely was correlated with postoperative VA. (Fig. 2).

Additionally, the morphological parameters were correlated with each other, as well as with age, duration of symptoms, and pre- and postoperative VA did for the most part (Fig. 2). In contrast, there was no correlation of the axial length with morphological or other quantitative parameters (see Fig. 2). MHs with VMT showed better final VA than those without VMT (final VA with VMT: $0.4(0.3 ; 0.5)$ vs. final VA without VMT: 0.5 (0.3; $0.8) ; p=0.003)$. Linear regression analysis showed that initial VA and the minimum linear diameter were correlated with final VA (Table 4).

\section{Discussion}

\section{Age/sex}

The higher proportion of females in our cohort as well as the mean age is consistent with previous reports $[2,6$, $9,11,15-18]$. In our cohort, younger age was correlated

Table 4 Multiple linear regression analysis of factors predicting postoperative VA

\begin{tabular}{|c|c|c|c|c|}
\hline Parameter & Coefficient & $95 \% \mathrm{Cl}$ & $\mathrm{p}$ & Sign. level \\
\hline MLD & $<0.001$ & 0.0003087 to 0.001009 & $<0.001$ & $* * *$ \\
\hline BD & $<0.001$ & $\begin{array}{l}-0.0001642 \text { to } \\
0.0002001\end{array}$ & 0.761 & ns \\
\hline H & $<0.001$ & $\begin{array}{l}-0.0004810 \text { to } \\
0.0006534\end{array}$ & 0.750 & ns \\
\hline $\mathrm{Ar}$ & 0.234 & -0.2975 to 0.4503 & 0.196 & ns \\
\hline Cy & $<0.001$ & $\begin{array}{l}-9.104 \mathrm{e}-006 \text { to } 8.774 \mathrm{e}- \\
006\end{array}$ & 0.739 & ns \\
\hline VA preop & 0.190 & 0.1308 to 0.4241 & 0.009 & $* *$ \\
\hline
\end{tabular}

In multiple linear regression analysis, only parameters with highly significant correlations (min. $p \leq 0.01$ ) with postoperative visual acuity and only patients with a closed MH $(n=164)$ were included. Macular hole indices were omitted due to multicollinearity/redundancy of the data. The aperture diameter and preoperative visual acuity were the strongest predictive factors for postoperative visual acuity. Abbreviations: $C l$ confidence interval, $M L D$ minimum linear diameter, $B D$ base diameter; $H$ max. Height, $A r$ area of $\mathrm{MH}, C y$ area of pseudocysts, VA visual acuity, ns not significant; ${ }^{* *}: p \leq 0.01 ;{ }^{* * *}: p \leq 0.001$ with better visual and surgical outcomes, which is in line with previous studies $[16,17,19]$. In contrast, in the works of Yuksel et al., Zou et al. and Steel et al., age was not a predictive factor for outcome $[2,9,20]$. This difference might be explained by differences in the study settings and the development of visual acuity after surgery over time. As Tirelli et al. showed, the increase in visual acuity takes longer in older patients [21]. Thus, the final visual acuity depends on the time period between surgery and the last follow-up. In our study, this was a median of 6 weeks; in the study by Gupta et al., it was 3 months [17]. Yuksel et al., Zou et al. and Steel et al., on the other hand, had a follow-up period of up to 12 months $[2,9,20]$.

\section{Duration of symptoms}

The influence of the duration of preoperative symptoms was analyzed by several other study groups, and they reported results similar to ours [2, 3, 22]. The duration of symptoms thus seems to be a suitable and simple survey parameter, although it might be biased due to its subjective perception.

We did not find a significant correlation between the duration of symptoms and the outcome. Nevertheless, we interpret the differences regarding this parameter between open and closed $\mathrm{MH}$ as a trend and thus might show statistical significance in a larger cohort. Fallico et al. proposed that small macular holes with a short duration of symptoms may be treated urgently, as there is a relation between better visual outcome and time from symptom onset to surgery for small macular holes [3].

\section{Visual acuity}

Regression analysis revealed that better preoperative VA was a strong predicator for better VA at the postoperative follow-up. Additionally, in the $\mathrm{MH}$ closed group, preoperative VA was significantly better than that in the MH persisting group. This is in accordance with previous studies with longer follow-up [2, 3, 7, 17, 22, 23]. Nevertheless, it 
has been shown that VA increases up to 2 years postoperatively $[23,24]$. Furthermore, as already noted above, the duration of postsurgical recovery also seems to be influenced by the patient's age. Tirelli et al. investigated postoperative visual acuity after 0,30 and 90 days [21]. They found that younger patients already reached the best possible VA after 30 days, which remained stable thereafter. Older patients, however, required more time to recover and reached the best outcome after 90 days [21]. The follow-up period in our study was limited because the surgeries were performed in a referral hospital, and after one follow-up examination, scheduled at 6 weeks after surgery, the patient was attended by the referring ophthalmologist. In clinical practice, patients with successful anatomical and visual outcomes are unlikely to be followed up long-term. This issue has previously been addressed by Fallico et al., who included only patients who were followed up for at least 1 year [3]. We fully concede that the short follow-up period of this study is one of the main limitations regarding postoperative visual outcome.

\section{Minimum linear diameter}

Although several of the evaluated parameters were correlated with the surgical and visual outcomes in our study, the minimum linear diameter (MLD) was the only parameter showing predictive properties in both the linear and logistic regression analyses. Although the significance of the MLD might be somewhat limited due to poor intra- and interindividual repeatability in manual OCT diameter measurements, as recently shown by Antonopoulou, the correlation of preoperative macular hole diameter and outcome was documented in several earlier studies [2, 3, 9, 16, 22, 25-27]. In our study, the MLD was a stronger predicator for postoperative VA than the basal diameter or the manually marked $\mathrm{MH}$ area (Fig. 2). In contrast to Steel et al., we found-as did all other comparable studies before-no significant difference in preoperative hole size between females and males [2]. Furthermore, while our cutoff value for an insufficient surgical outcome $(>392.5 \mu \mathrm{m})$ corresponds closely to the cutoff values for large macular holes by the International Vitreomacular Traction Study (IVTS) group, Steel et al. proposed a minimum linear diameter of $\sim 500 \mu \mathrm{m}$ as the threshold where the success rate starts to decline $[2,14]$. The receiver operating characteristic curve for surgical failure and MLD in their study reached an area under the curve (AUROC) of $77.9 \%$; in our study, it reached $90.1 \%$. Ch'ng et al. proposed even higher threshold values for large MHs. They reported a cutoff value of $630 \mu \mathrm{m}$, yielding a Youden index $(\mathrm{J})$ of 0.46 [28]. The Youden Index is a frequently used summary measure of the ROC curve. It both measures the effectiveness of a diagnostic marker (here: MLD) and enables the selection of an optimal cutoff point for this marker to determine the outcome (here: $\mathrm{MH}$ closed vs. $\mathrm{MH}$ persisting). It ranges between 0 and 1. A value of 0 indicates that it has no predictive value, and a value of 1 represents the perfect test or biomarker. A Youden index ( $\mathrm{J}$ ) of 0.46 , as reported by Ch'ng et al., corresponds to a relatively low to moderate level of effectiveness/separation. In contrast, the Youden index for our cutoff of $392 \mu \mathrm{m}$ was 0.72 , corresponding to a very good level of effectiveness/separation (see Table 3).

\section{VMT}

It is generally known that increased vitreomacular adhesion can lead to VMT and subsequently to a macular hole due to anterior and posterior traction forces [29-33]. In contrast to Philippakis et al. [34], we found a marginally significantly higher closure rate $(p=0.036)$ and significantly better visual acuity $(p=0.003)$ in patients with VMT than in patients without VMT. However, Philippakis et al. ( $n=77$ eyes) assumed that a larger study population would have resulted in significant differences [34]. One explanation for the better morphological and functional outcome in our study could be that patients with VMT presented with beneficial factors such as lower overall age and smaller hole size. Thus, it is not useful as a prognostic indicator.

\section{Perifoveal pseudocysts}

The areas of parafoveal intraretinal pseudocysts were correlated in our study with a low closure rate and with low postoperative visual acuity. In the study by RuizMoreno et al., the mean pre- and postoperative VA was lower in patients with cystic retinal changes than in those without [6]. Yuksel et al. also found a correlation of pseudocysts and persistent macular holes but no correlation with postoperative visual acuity [9]. In contrast, Brockmann et al. found that the presence of parafoveal pseudocysts was associated with a higher closure rate. However, in their work, the presence of perifoveal pseudocysts was only assessed qualitatively [10]. In a similar approach by Chhablani et al., the presence of cystic edges was associated with anatomical success and a better final VA [12]. Liang et al. suggested that a cystic configuration might contribute to spontaneous closure of the macular hole [1]. Venkatesh et al. calculated the macular hole cystoid space area index (MCSAI; MCSAI = macular hole cystoid space area/total MH area) and showed its possible predictive value.

\section{Lens status}

Consistent with our findings, several previous studies did not find a significant impact of lens status and macular hole surgery combined with cataract surgery on 
anatomical or visual outcomes [2, 9, 18, 19]. Essex et al., however, found that combined phacovitrectomy was associated with better VA postoperatively (vs. vitrectomy surgery alone), a difference that vanished when eyes went on to have subsequent cataract surgery [23]. Due to the relatively short follow-up in our study, phakic patients had not developed visually significant cataracts, as in the work by Steel et al. [2].

\section{Indices}

In our study, MHI, DHI and THI were correlated with postoperative visual acuity (VA), although DHI showed a rather weak correlation. In the literature, the results regarding the correlation of the indices and final VA are mostly comparable. In several studies, a correlation between MHI and postoperative VA was shown $[6,8,9,11,12]$. Additionally, a correlation with the tractional index THI has been described $[6,8,12]$. Nevertheless, there are some controversial results. While Chablani et al. also confirmed the correlation of THI with VA, in their study, there was no correlation between final VA and MHI and DHI. Ruiz-Moreno et al. found that MHI and THI, but not DHI, were correlated significantly with postoperative VA [6].

Regarding differences in the indices in the surgical outcome group, Wakely et al. found an association between anatomical success and MHI but not THI [8]. Venkatesh et al. showed that MHI and THI were capable of predicting anatomical success [35]. Chhablani et al. found a significant correlation of all three indices (THI, MHI and DHI) with anatomical success [12].

\section{Limitations}

As mentioned above, the main limitation of our study is the short follow-up time. Additionally, the size of our cohort might be considered a limiting factor. While there are some studies with larger cohorts in general, there are only a few with larger cohorts with such an extensive analysis of parameters. To our knowledge, our study is the largest cohort for some of the analyzed parameters, such as intraretinal pseudocysts. Nevertheless, some parameters regarding the macular hole anatomy, such as the hole angle, volume and base area, were not evaluated [36-38]. Additionally, other very specific details of retinal changes, e.g., in the ellipsoid zone, photoreceptor structure, ganglioncell thickness and choroidal thickness and perfusion, have not been studied [39-42]. Furthermore, the inclusion of 11 patients with $\mathrm{MH}$ in both eyes could possibly result in a statistical bias caused by correlations associated with binocularity. To rule out such a bias, all results were recalculated without those patients. This did not change the significance levels or the results themselves. For this reason, binocular patients were not excluded.

\section{Conclusion}

The aim of this retrospective study was to analyze factors influencing the outcome of surgically treated $\mathrm{MH}$ and to identify the factor with the strongest predictive power. The minimum linear diameter was the only parameter showing predictive properties in the regression analyses regarding both surgical and functional outcome. Thus, in our opinion, the results of this study show that there is no need for complicated measurements of the macular hole area or cyst areas or for the calculation of any indices. The minimum linear diameter serves as an easily assessed parameter with the best predictive properties. This result is of great importance for clinical practice, as it simplifies the postsurgical prognosis.

\section{Acknowledgments \\ Not applicable.}

\section{Authors' contributions}

D.E., K.K., J.S., and M.R. contributed to the conception and design of the study. N.S. and M.R. were mainly responsible for the acquisition of data. M.R., N.S., and L.J. wrote the main manuscript text. M.R. and N.S. were responsible for interpretation of data/statistics and prepared the figures. All authors reviewed the manuscript critically for important intellectual content. All authors gave final approval of the version to be published.

\section{Funding}

Open Access funding enabled and organized by Projekt DEAL. No funding was obtained for this study.

\section{Availability of data and materials}

The datasets used and/or analyzed during the current study are available from the corresponding author on reasonable request.

\section{Declarations}

Ethics approval and consent to participate

The study is a strictly retrospective data analysis. The study was reported in writing to the Ethics Committee of the North Rhine Medical Association Association (Ärztekammer Nordrhein) in June 2017. Due to the study type (retrospective data analysis), approval was given, but because of the regulations in use at that time, no ethics procedure was initiated. For the same reason, after consultation with North Rhine Medical, consent for participation was deemed unnecessary.

\section{Consent for publication}

Not applicable.

\section{Competing interests \\ Not applicable.}

\section{Author details}

${ }^{1}$ Department of Ophthalmology, Heinrich-Heine University Düsseldorf, Universitätsaugenklinik Düsseldorf, Moorenstr. 5, 40225 Düsseldorf, Germany. ${ }^{2}$ Augenklinik Tausendfensterhaus, Duisburg, Germany. ${ }^{3}$ Department of Ophthalmology, University Clinic Marburg, Marburg, Germany.

Received: 29 July 2021 Accepted: 30 October 2021

Published online: 18 November 2021

References

1. Liang X, Liu W, Ohira A. Characteristics and risk factors for spontaneous closure of idiopathic full-thickness macular hole. J Ophthalmol. 2019;2019. https://www.hindawi.com/journals/joph/2019/4793764/. 
2. Steel DH, Donachie PHJ, Aylward GW, Laidlaw DA, Williamson TH, Yorston D, et al. Factors affecting anatomical and visual outcome after macular hole surgery: findings from a large prospective UK cohort. Eye. 2021;35(1):316-25.

3. Fallico M, Jackson TL, Chronopoulos A, Hattenbach LO, Longo A, Bonfiglio $\checkmark$, et al. Factors predicting normal visual acuity following anatomically successful macular hole surgery. Acta Ophthalmol. 2020;1-6.

4. Liu P, Sun Y, Dong C, Song D, Jiang Y, Liang J, et al. A new method to predict anatomical outcome after idiopathic macular hole surgery. Graefe's Arch Clin Exp Ophthalmol. 2016;254(4):683-8 [cited 2017 Jan 19]. Available from: http://www.ncbi.nlm.nih.gov/pubmed/26254111.

5. Gogia V, Kumar P, Sehra S, Gupta S, Kumar A. Evaluation of predictors for anatomical success in macular hole surgery in Indian population. Indian . Ophthalmol. 2014;62(12):1141 [cited 2017 Jan 19]. Available from: http:// www.ncbi.nlm.nih.gov/pubmed/25579358.

6. Ruiz-Moreno JM, Staicu C, Piñero DP, Montero J, Lugo F, Amat P. Optical coherence tomography predictive factors for macular hole surgery outcome. Br J Ophthalmol. 2008;92(5):640-4.

7. Kusuhara S, Negi A. Predicting visual outcome following surgery for idiopathic macular holes. Ophthalmologica. 2014;231(3):125-32.

8. Wakely L, Rahman R, Stephenson J. A comparison of several methods of macular hole measurement using optical coherence tomography, and their value in predicting anatomical and visual outcomes. Br J Ophthalmol. 2012;96(7):1003-7.

9. Yuksel K, Goker YS, Yazici AT, Ozkaya A, Cosar G. Can Perifoveal Pseudocyst area be a prognostic factor in macular hole surgery? Medicine (Baltimore). 2014;93(28):e182 [cited 2017 Jan 19]. Available from: http://www. ncbi.nlm.nih.gov/pubmed/25526432.

10. Brockmann T, Steger C, Weger M, Wedrich A, Haas A. Risk assessment of idiopathic macular holes undergoing vitrectomy with dye-assisted internal limiting membrane peeling. Retina. 2013;33(6):1132-6.

11. Kusuhara S, Teraoka Escaño MF, Fujii S, Nakanishi Y, Tamura Y, Nagai A, et al. Prediction of postoperative visual outcome based on hole configuration by optical coherence tomography in eyes with idiopathic macular holes. Am J Ophthalmol. 2004;138(5):709-16.

12. Chhablani J, Khodani M, Hussein A, Bondalapati S, Rao HB, Narayanan R, et al. Role of macular hole angle in macular hole closure. Br J Ophthalmol. 2015;99(12):1634-8

13. Jay Chhablani RN. Outcomes of double frequency Nd:YAG laser Membranotomy for Premacular hemorrhage secondary to Valsalva retinopathy. J Clin Exp Ophthalmol. 2014;05(06):10-2 Available from: https://www.omics online.org/open-access/outcomes-of-double-frequency-ndyag-lasermembranotomy-for-premacular-2155-9570.1000376. php?aid=36465.

14. Duker JS, Kaiser PK, Binder S, De Smet MD, Gaudric A, Reichel E, et al. The international vitreomacular traction study group classification of vitreomacular adhesion, traction, and macular hole. Ophthalmology. 2013;120(12):2611-9 Available from: https://doi.org/10.1016/j.ophtha. 2013.07.042.

15. Darian-Smith E, Howie AR, Allen PL, Vote BJ. Tasmanian macular hole study: whole population-based incidence of full thickness macular hole. Clin Exp Ophthalmol. 2016:44(9):812-6.

16. Ullrich S, Haritoglou C, Gass C, Schaumberger M, Ulbig MW, Kampik A. Macular hole size as a prognostic factor in macular hole surgery. Br J Ophthalmol. 2002;86(4):390-3 Available from: http://www.pubmedcent ral.nih.gov/articlerender.fcgi?artid=1771090\&tool=pmcentrez\&rende rtype $=$ abstract

17. Gupta B, Laidlaw DAH, Williamson TH, Shah SP, Wong R, Wren S. Predicting visual success in macular hole surgery. Br J Ophthalmol. 2009;93(11):1488-91.

18. Forsaa VA, Lindtjørn B, Kvaløy JT, Frøystein T, Krohn J. Epidemiology and morphology of full-thickness macular holes. Acta Ophthalmol. 2018;96(4):397-404

19. Kim Y, ES KIM, Yu S-Y, Kwak HW. Age-related clinical outcome after macular hole surgery. Retina. 2017;37(1):80-7 [cited 2017 Jan 19]. Available from: http://www.ncbi.nlm.nih.gov/pubmed/28005719.

20. Zou JL, Zeng J. The macular microstructure repair and predictive factors of surgical outcomes after vitrectomy for idiopathic macular hole. Int J Ophthalmol. 2019;12(5):852-7.

21. Tirelli F, Sasso P, Scupola A. Idiopathic macular hole: postoperative morpho-functional assessment and prognostic factors for recovery of visual acuity. Ann Ist Super Sanita. 2013;49(3).
22. Jaycock PD, Bunce C, Xing W, Thomas D, Poon W, Gazzard G, et al. Outcomes of macular hole surgery: implications for surgical management and clinical governance. Eye. 2005;19(8):879-84.

23. Essex RW, Hunyor AP, Moreno-Betancur M, Yek JTO, Kingston ZS, Campbell WG, et al. The visual outcomes of macular hole surgery: a registrybased study by the Australian and new Zealand Society of Retinal Specialists. Ophthalmol Retin. 2018;2(11):1143-51.

24. Karacorlu M, Sayman Muslubas I, Ersoz MG, Hocaoglu M, Arf S. When does visual acuity stabilize after macular hole surgery? Five-year follow-up of surgery for idiopathic macular hole. Acta Ophthalmol. 2019;97(1):e136-7.

25. Ip MS, Baker BJ, Duker JS, Reichel E, Baumal CR, Gangnon R, et al. Anatomical outcomes of surgery for idiopathic macular hole as determined by optical coherence tomography. Arch Ophthalmol. 2002;120(1):29-35.

26. Wirbelauer AC, Kolarov D, Just A, med Christopher Wirbelauer KP, Wirbelauer C, Kolarov D, et al. Einfluss der Lochbreite auf Visus, Endotamponade und Verschlussrate beim Makulaforamen. Klin Monatsbl Augenheilkd. 2016;233(12):1362-6 [cited 2017 Jan 19]. Available from: http://www.ncbi. nlm.nih.gov/pubmed/27984839.

27. Antonopoulou PG, Baumann C, Jalil A, Dhawahir-Scala F, Muñoz-Sanz $\mathrm{N}$, Lu VHJ, et al. How big is the hole? Measuring intra- and interindividual agreement in macular hole size measurements. Curr Eye Res. 2020;45(8):1000-4 Available from: https://doi.org/10.1080/02713683. 2019.1708956.

28. Ch'ng SW, Patton N, Ahmed M, Ivanova T, Baumann C, Charles S, et al. The Manchester large macular hole study: is it time to reclassify large macular holes? Am J Ophthalmol. 2018;195:36-42 Available from: https://doi.org/ 10.1016/j.ajo.2018.07.027.

29. Johnson MW, Van Newkirk MR, Meyer K, a. Perifoveal vitreous detachment is the primary pathogenic event in idiopathic macular hole formation. Arch Ophthalmol. 2001;119(2):215-22.

30. Smiddy WE, Flynn HW. Pathogenesis of macular holes and therapeutic implications. Am J Ophthalmol. 2004;137(3):525-37.

31. Gaudric A, Haouchine B, Massin P, Paques M, Blain P, Erginay A. Macular hole formation: new data provided by optical coherence tomography. Arch Ophthalmol. 1999;117(6):744-51.

32. Haouchine B, Massin P, Gaudric A. Foveal pseudocyst as the first step in macular hole formation: a prospective study by optical coherence tomography. Ophthalmology. 2001;108(1):15-22.

33. Steel DHW, Lotery AJ. Idiopathic vitreomacular traction and macular hole: a comprehensive review of pathophysiology, diagnosis, and treatment. Eye. 2013;27(SUPPL):S1-21 Available from: https://doi.org/10.1038/eye.2013.212

34. Philippakis E, Amouyal F, Couturier A, Boulanger-Scemama E, Gaudric A, Tadayoni R. Size and vitreomacular attachment of primary full-thickness macular holes. Br J Ophthalmol. 2017;101(7):951-4.

35. Venkatesh R. Newer indices for predicting macular hole closure in idiopathic macular holes: a retrospective, comparative study. Indian J Ophthalmol. 2017;17(1):1 Available from: http://www.ncbi.nlm.nih.gov/ pubmed/28331284\%0A. http://www.pubmedcentral.nih.gov/articleren der.fcgi?artid=PMC5354527\%5Cn. http://bmcpsychiatry.biomedcentral. com/articles/10.1186/1471-244X-11-49\%5Cn. http://bmcophthalmol. biomedcentral.com/articles/10.1186/s12886.

36. Xu D, Yuan A, Kaiser PK, Srivastava SK, Singh RP, Sears JE, et al. A novel segmentation algorithm for volumetric analysis of macular hole boundaries identified with optical coherence tomography. Investig Ophthalmol Vis Sci. 2013;54(1):163-9.

37. Unsal E, Cubuk MO, Ciftci F. Preoperative prognostic factors for macular hole surgery: which is better? Oman J Ophthalmol. 2019; 12(1):20-24.

38. Chow DR, Chaudhary KM. Optical coherence tomography-based positioning regimen for macular hole surgery. Retina. 2015;35(5):899-907 [cited 2017 Jan 19]. Available from: http://www.ncbi.nlm.nih.gov/pub$\mathrm{med} / 25602632$

39. De Sisternes L, Hu J, Rubin DL, Leng T. Visual prognosis of eyes recovering from macular hole surgery through automated quantitative analysis of spectral-domain optical coherence tomography (SD-OCT) scans. Investig Ophthalmol Vis Sci. 2015;56(8):4631-43 [cited 2017 Jan 22]. Available from: http://www.ncbi.nlm.nih.gov/pubmed/26200503.

40. Hansen S, Batson S, Weinlander KM, Cooper RF, Scoles DH, Karth PA, et al. ASSESSING PHOTORECEPTOR STRUCTURE AFTER MACULAR HOLE CLOSURE. Retin Cases Brief Rep. 2015;9(1):15-20 [cited 2017 Jan 19]. Available from: http://www.ncbi.nlm.nih.gov/pubmed/25525907. 
41. Hoon Seo K, Woo Kwak H, Seo KH, Yu S-Y, Kwak HW. Topographic changes in macular ganglion cell-inner plexiform layer thickness after vitrectomy with indocyanine green-guided internal limiting membrane peeling for idiopathic macular hole. Retina. 2015;35(9):1828-35 [cited 2017 Jan 19]. Available from: http://www.ncbi.nlm.nih.gov/pubmed/25923957.

42. Kim SH, Kim HK, Yang JY, Lee SC, Kim SS. Visual recovery after macular hole surgery and Related prognostic factors. Korean J Ophthalmol. 2018;32(2):140.

\section{Publisher's Note}

Springer Nature remains neutral with regard to jurisdictional claims in published maps and institutional affiliations.
Ready to submit your research? Choose BMC and benefit from:

- fast, convenient online submission

- thorough peer review by experienced researchers in your field

- rapid publication on acceptance

- support for research data, including large and complex data types

- gold Open Access which fosters wider collaboration and increased citations

- maximum visibility for your research: over 100M website views per year

At BMC, research is always in progress.

Learn more biomedcentral.com/submissions 